\title{
Potential anti-vitiligo properties of cynarine extracted from Vernonia anthelmintica (L.) Willd
}

\author{
NURAMINA MAMAT ${ }^{1,2}$, XUE YING LU $^{3}$, MAIDINA KABAS $^{1}$ and HAJI AKBER AISA ${ }^{1,3}$ \\ ${ }^{1}$ Key Laboratory of Plant Resources and Chemistry of Arid Zone, Xinjiang Technical Institute of Physics and Chemistry, \\ Chinese Academy of Sciences, Ürümqi, Xinjiang 830011; ${ }^{2}$ University of the Chinese Academy of Sciences, Beijing 100039 ; \\ ${ }^{3}$ State Key Laboratory Basis of Xinjiang Indigenous Medicinal Plants Resource Utilization, Xinjiang Technical Institute of \\ Physics and Chemistry, Chinese Academy of Sciences, Ürümqi, Xinjiang 830011, P.R. China
}

Received April 3, 2018; Accepted August 10, 2018

DOI: $10.3892 /$ ijmm.2018.3861

\begin{abstract}
Vitiligo is a depigmentation disorder of the skin. It is primarily caused by the destruction of melanocytes or obstruction of the melanin synthesis pathway. Melanin is a type of skin pigment that determines skin color. The seeds of Vernonia anthelmintica (L.) Willd (Kaliziri) are used for treating skin diseases including vitiligo in traditional Uyghur medicine. 1,5-Dicaffeoylquinic acid (1,5-diCQA) is a natural polyphenolic compound widely distributed in plants and extracted from Kaliziri seeds. Therefore, in the present study, the effect of 1,5-diCQA on melanin synthesis in B16 cell was evaluated, and its molecular mechanism was explored. The results indicated that 1,5-diCQA treatment of B16 cells stimulated an increase of intracellular melanin level and tyrosinase (TYR) activity without cytotoxicity. Reverse transcription quantitative polymerase chain reaction results also indicated that 1,5-diCQA may markedly improve the protein expression and RNA transcription of microphthalmia-associated transcription factor (MITF), melanogenic enzyme Tyr, tyrosinase-related protein 1 (TRP 1) and tyrosinase-related protein 2 (TRP 2). Additional results identified that 1,5-diCQA may promote the phosphorylation of p38 mitogen-activated protein kinase (p38 MAPK) and extracellular signal-regulated kinase (ERK) MAPK. Notably, the increased levels of intracellular melanin synthesis and tyrosinase expression induced by 1,5-diCQA treatment were significantly attenuated by the protein kinase A (PKA) inhibitor H-89. Intracellular cyclic adenosine monophosphate (cAMP) concentration and phosphorylation of cAMP-response element binding protein was increased following 1,5-diCQA treatment. These results
\end{abstract}

Correspondence to: Professor Haji Akber Aisa, Key Laboratory of Plant Resources and Chemistry of Arid Zone, Xinjiang Technical Institute of Physics and Chemistry, Chinese Academy of Sciences, 40-1 South Beijing Road, Urumqi, Xinjiang 830011, P.R. China E-mail: haji@ms.xjb.ac.cn

Key words: 1,5-dicaffeoylquinic acid, vitiligo, melanogenesis, mitogen-activated protein kinase signal pathway indicated that 1,5-diCQA stimulated melanogenesis via the MAPK and cAMP/PKA signaling pathways in B16 cells, which has potential therapeutic implications for vitiligo.

\section{Introduction}

Vitiligo is a depigmentation disorder of the skin clinically characterized by the appearance of disfiguring circumscribed skin macules. It is hypothesized that the disease primarily results from the destruction of melanocytes or obstruction of the melanin synthesis pathway $(1,2)$. Melanin is an essential component in the pigmentary system of the skin, which serves a vital role in the prevention from damage by ultraviolet light (3). Melanocytes synthesize melanin via a process termed melanogenesis in the melanosome, a specialized organelle of melanocytes (4). Melanogenesis is a physiological process leading to the production of melanin pigment and a crucial step for the regulation of melanocyte functions, including photoprotection (5). Melanogenesis is regulated by melanogenic enzymes, including tyrosinase (TYR), tyrosinase-related protein 1 (TRP 1) and tyrosinase-related protein 2 (TRP 2) (6). TYR directly mediates the production of melanin through the oxidation of melanogenesis-associated substrates tyrosine (7). Microphthalmia-associated transcription factor (MITF) is a master regulator of the transcription of genes involved in melanin synthesis (8).

Previous studies have identified signaling pathways that mediate melanogenesis A summary obtained from Niu and Aisa (9) is presented in Fig. 1. Among them, the p38 mitogen-activated protein kinase (p38 MAPK) pathway may upregulate melanogenesis by increasing MITF expression $(9,10)$. The extracellular signal-regulated kinase mitogen-activated protein kinase (ERK MAPK)-dependent MITF expression pathway is also involved in melanogenesis (11). In addition, the cyclic adenosine monophosphate (cAMP)/protein kinase A (PKA) signal pathway is one of the primary pathways that may increase the expression of MITF, which is also associated with cAMP responsive element binding (CREB) and CREB binding protein (CBP) (12). Previously, the Wnt/ $\beta$-catenin signal pathway was identified to serve an important role in melanin synthesis through the nuclear mediator MITF (13). 
Vernonia anthelmintica (L.) Willd. (Kaliziri), a member of the Asteraceae family, is an erect forb or shrub that is broadly distributed in subtropical and tropical areas throughout Asia and Africa (14). It has been demonstrated that Kaliziri possesses a number of pharmacological properties, including anti-inflammatory, antibacterial, antioxidant, hypoglycemic and antithrombotic activities (15). The seeds are used in traditional therapy as treatment for skin diseases including vitiligo (16).

1,5-Dicaffeoylquinic acid (1,5-diCQA; Fig. 2) is a class of natural polyphenolic compounds widely distributed in plants $(17,18)$. Previously, it was also identified that 1,5-diCQA exhibits antioxidant signal properties that upregulate glutathione synthesis by stimulating the nuclear factor-like 2 pathway in astrocytes and protects them from cell death (19). 1,5-diCQA also protects primary neurons from amyloid $\beta$ 1-42-induced apoptosis via the phosphoinositide 3-kinase/protein kinase B signal pathway (20).

Therefore, the present study evaluated the effect of 1,5-diCQA, which was isolated from Kaliziri seeds, on melanin synthesis in murine B16 cells, and examined its molecular mechanism.

\section{Materials and methods}

1,5-DiCQA extraction. 1,5-DiCQA was extracted from Vernonia anthelmintica (L.) Willd. Briefly, Vernonia anthelmintica seeds $(1 \mathrm{~kg})$ were pulverized. Ethanol $(40 \%)$ was added and refluxed at $80^{\circ} \mathrm{C}$ three times, each time for $1 \mathrm{~h}$. The extracts were combined and concentrated. This extract was subsequently purified by HPD-300 macroporous resin (diameter, 1:8; loading volume, $6 \mathrm{BV}$; Cangzhou Bon Adsorber Technology Co., Ltd., Cangzhou, China). Following drying, a $60 \mathrm{~g}$ powder was obtained. The powder was taken and dissolved in ethanol, and separated by medium pressure preparative chromatography. At last, the fraction was separated and purified by semi-preparative chromatography to obtain 1,5-diCQA, according to a previously described method (21).

Materials. The obtained 1,5-diCQA (white solid; purity, 98\%) was dissolved in dimethyl sulfoxide (DMSO; $100 \mathrm{mM}$ ) and stored at $-20{ }^{\circ} \mathrm{C}$ as a stock solution. ERK (cat. no. 4696), phosphorylated (p)-ERK (Thr202/Tyr204; cat. no. 9106), p38 (cat. no. 9212), p-P38 (Thr180/Tyr182; cat. no. 5140), CREB (cat. no. 9104), p-CREB (Ser133; cat. no. 9196), glycogen synthase kinase $3 \beta$ (GSK-3 $\beta$; cat. no. 9832), p-GSK-3 $\beta$ (cat. no. 9323), $\beta$-catenin (cat. no. 8480) and $p-\beta$-catenin (ser675; cat. no. 4176) antibodies were purchased from Cell Signaling Technology, Inc., (Danvers, MA, USA). p-MITF (cat. no. SAB4301514) antibody, phenyl methyl sulfonyl fluoride and the components of the whole cell lysis buffer for western blot analysis were obtained from Sigma-Aldrich, Merck KGaA (Darmstadt, Germany). $\beta$-actin antibody (cat. no. MA1115), rabbit anti-goat secondary antibody (cat. no. BA1060), goat anti-rabbit secondary antibody (cat. no. BA1054) and goat anti-mouse secondary antibody (cat. no. BA1050) were purchased from Wuhan Boster Biological Technology, Ltd., (Wuhan, China). TYR (cat. no. sc-7833), MITF (cat. no. sc-52938), TRP 1 (cat. no. sc-25543) and TRP 2 (cat. no. sc-25544) antibodies were purchased from Santa Cruz Biotechnology, Inc. (Dallas, TX,
USA). The bicinchoninic acid (BCA) protein assay kit was purchased from Beijing Biomed Gene Technology Co., Ltd. (Beijing, China). The ERK (PD98059), JNK (SP600125) and p38 MAPK inhibitors (SB203580) were purchased from Beyotime Institute of Biotechnology (Haimen, China). The JNK inhibitor (SP600125) was obtained from EMD Biosciences (EMD Millipore, Billerica, MA, USA) and dissolved in DMSO. Deoxynucleotide triphosphates (dNTPs, cat. no. BH7201B ) were purchased from TAKARA BIO INC. (Yokohama, Japan). The Recombinant RNasin Ribonuclease Inhibitor (cat. no. N2511) and $100 \mathrm{U}$ Moloney murine leukemia virus (M-MLV) reverse transcriptase (cat. no. M170A) were purchased from Promega Corporation (Madison, WI, USA). Power SYBR ${ }^{\mathrm{TM}}$-Green PCR Master mix (cat. no. 4367659) was purchased from Applied Biosystems (Thermo Fisher Scientific, Inc., Waltham, MA, USA). 8-Methoxypsoralen (8-MOP, cat. no. M3501) was purchased from Sigma-Aldrich (Merck KGaA) and dissolved in DMSO $(50 \mathrm{mM})$ for storage at $-20^{\circ} \mathrm{C}$ as a stock solution.

Cell culture. B16 murine melanoma cells were obtained from the Cell Bank of Type Culture Collection of the Chinese Academy of Sciences, (Beijing, China). Cells were grown in Dulbecco's modified Eagle's medium (Gibco; Thermo Fisher Scientific, Inc.) supplemented with $10 \%$ heat-inactivated fetal bovine serum (Gibco; Thermo Fisher Scientific, Inc.), $100 \mu \mathrm{g} / \mathrm{ml}$ streptomycin and $100 \mathrm{U} / \mathrm{ml}$ penicillin (Gibco; Thermo Fisher Scientific, Inc.; cat. no. 15140-122) in a humidified atmosphere with $5 \% \mathrm{CO}_{2}$ at $37^{\circ} \mathrm{C}$.

Cell viability assay. To examine the effects of 1,5-diCQA on cell viability, a TransDetect Cell Counting kit (CCK) assay (cat. no. FC101; Beijing Transgen Biotech, Co., Ltd., Beijing, China) was performed according to the manufacturer's protocol. Briefly, B16 cells were seeded in 96-well plates $\left(5 \times 10^{3}\right.$ cells/well) and allowed to adhere at $37^{\circ} \mathrm{C}$ for $12 \mathrm{~h}$. Cells were then treated with $0,5,25,50,100,200$ or $400 \mu \mathrm{M}$ 1,5-diCQA for $48 \mathrm{~h}$. Following treatment, $10 \mu \mathrm{l} \mathrm{CCK}$ solution was added into each well and cells were incubated at $37^{\circ} \mathrm{C}$ for an additional $2 \mathrm{~h}$. Optical absorbance was determined at $450 \mathrm{~nm}$ with a Spectra Max M5 plate reader (Molecular Devices, LLC, Sunnydale, CA, USA). The absorbance of cells without treatment was considered as $100 \%$ cell survival. Each treatment was performed in quintuplicate, and each experiment was repeated three times. To observe the cell morphology, B16 cells were seeded in 6-well plates $\left(1 \times 10^{4}\right.$ cells/well) and allowed to adhere at $37^{\circ} \mathrm{C}$ for $12 \mathrm{~h}$. Cells were subsequently treated with $0,5,50$ or $100 \mu \mathrm{M}$ 1,5-diCQA for $48 \mathrm{~h}$. Cell morphology was observed and images were captured at room temperature using a LEICA DMI 8 fluorescence inversion microscope (magnification, x200; Leica Microsystems GmbH, Wetzlar, Germany).

Melanin content assay. The effect of 1,5-diCQA on melanogenesis in B16 cells was investigated according to a previously published protocol, with certain modifications (22). More specifically, intracellular melanin content was measured by using the $\mathrm{NaOH}$ dissolution method: $\mathrm{B} 16$ cells were seeded in a 6-well plate at a density of $2 \times 10^{5}$ cells/well, and then allowed to attach for $12 \mathrm{~h}$. Then, cells were treated with 1,5-diCQA at 


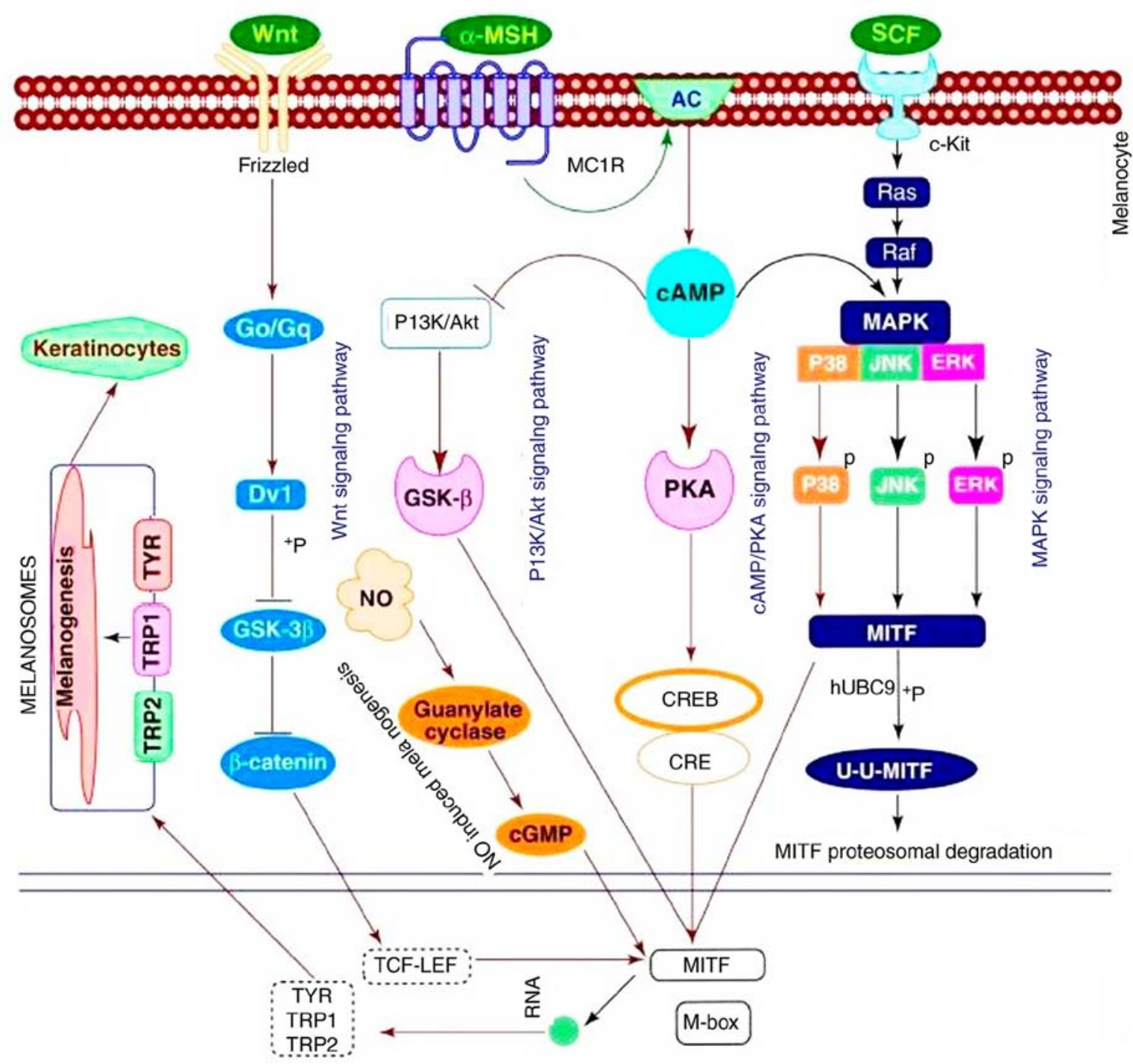

Figure 1. Melanogenesis. Obtained from Niu and Aisa (9). TYR, tyrosinase; TRP-1, tyrosinase-related protein 1; TRP-2, tyrosinase-related protein 2; MITF, microphthalmia-associated transcription factor; MAPK, mitogen-activated protein kinase; P38, p38 MAPK; ERK, extracellular signal-regulated kinase; JNK,

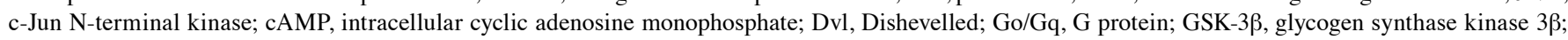
CRE, cAMP-response element; CREB, cAMP-response element binding protein; CBP, CREB binding protein; TCF-LEF, T cell factor-lymphoid enhancer factor; PKA, protein kinase A; $\alpha$-MSH, $\alpha$ melanocyte stimulating hormone; PI3K, phosphoinositide 3-kinase; Akt, protein kinase B; NO, nitric oxide; MC1R, melanocortin 1 receptor; SCF, stem cell factor; AC, adenylyl cyclase; c-Kit, proto-oncogene c-Kit.

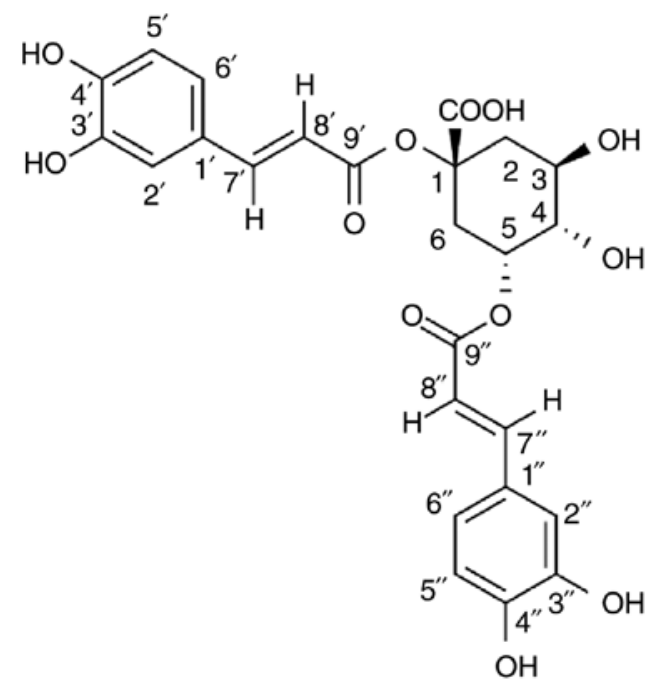

Figure 2. Chemical structure of 1,5-dicaffeoylquinic acid.
$0,5,50,100 \mu \mathrm{M}$ or $8-\mathrm{MOP}$ at $50 \mu \mathrm{M}$ for $48 \mathrm{~h}$, and SB203580 (10 $\mu \mathrm{M})$; PD98059 $(1 \mu \mathrm{M})$; SP600125 $(10 \mu \mathrm{M})$ for $2 \mathrm{~h}$ prior to 1,5-diCQA application. Cells were washed with PBS and harvested with $100 \mu 1$ radioimmunoprecipitation assay lysis buffer (Beyotime Institute of Biotechnology) in 1.5 Eppendorf (Ep) tubes. Samples were centrifuged at $-4^{\circ} \mathrm{C}$ and $12,000 \mathrm{x} \mathrm{g}$ for $20 \mathrm{~min}$, and the supernatant was obtained to determine the protein concentrations. Sediment was dissolved in $150 \mu \mathrm{l}$ $1 \mathrm{M} \mathrm{NaOH}$ (with $10 \% \mathrm{DMSO}$ ) for $1 \mathrm{~h}$ at $80^{\circ} \mathrm{C}$, and solubilized melanin was measured at $405 \mathrm{~nm}$. The amount of melanin was calculated by normalizing the total melanin values with the protein content.

Tyrosinase activity assay. Tyrosinase activity was estimated by measuring the rate of L-DOPA oxidation as previously described, with certain modifications (23). B16 cells were seeded in a 6 -well plate at a density of $3 \times 10^{5}$ cells/well and allowed to attach for $12 \mathrm{~h}$. Then, cells were treated with 
1,5-diCQA at $0,5,50,100 \mu \mathrm{M}$ or 8 -MOP at $50 \mu \mathrm{M}$ for $24 \mathrm{~h}$; SB203580 $(10 \mu \mathrm{M})$; PD98059 $(1 \mu \mathrm{M})$; or SP600125 $(10 \mu \mathrm{M})$ for $2 \mathrm{~h}$ prior to 1,5-diCQA application. Cells were then washed with ice-cold PBS twice, $100 \mu 1$ lysis buffer (1\% sodium deoxycholate and $1 \%$ Triton $\mathrm{X}-100$ in PBS) was added and cells were collected with a cell scraper into an Ep tube. All tubes were incubated at $-20^{\circ} \mathrm{C}$ for $30 \mathrm{~min}$, and then centrifuged at $-4^{\circ} \mathrm{C}$ and $12,000 \mathrm{x}$ g for $20 \mathrm{~min}$. Following centrifugation, the supernatants were obtained for determining the protein concentrations and tyrosinase activity assay. Protein concentrations were determined using the BCA protein assay kit. A reaction mixture containing $90 \mu \mathrm{l}$ cell lysate and $10 \mu 110 \mathrm{mM}$ L-DOPA was added to each well of a 96-well plate for each sample. Following a 20-60-min incubation (according to the content of dopachrome formation) at $37^{\circ} \mathrm{C}$ in the dark, the dopachrome product was detected at $490 \mathrm{~nm}$ by a multi-plate reader (Spectra Max M5/M5e), The tyrosinase activity of each sample was calculated and corrected for the concentrations of proteins, and normalized with protein content levels.

Reverse transcription quantitative polymerase chain reaction (RT-qPCR). Total cellular RNA was prepared from B16 cells using TRIzol reagent ${ }^{\circledR}$ (Invitrogen; Thermo Fisher Scientific, Inc.) according to the manufacturer's protocol. The quality of RNA samples was assessed using $1.5 \%$ agarose gel electrophoresis, at $100 \mathrm{~V}$ for $20 \mathrm{~min}$ and was subsequently analyzed using Quantity One version 3 (Bio-Rad Laboratories, Inc., Hercules, CA, USA). The concentration of total RNA was determined using a NanoDrop 2000 spectrophotometer (NanoDrop Technologies; Thermo Fisher Scientific, Inc., Wilmington DE, USA). cDNA was synthesized from $1.0 \mu \mathrm{g}$ total RNA using the Reverse Transcriptase M-MLV according to the protocol of the manufacturer. The cDNA from each sample was used as a template in the RT-qPCR to detect the mRNA level of the 1,5-diCQA target genes. qPCR was conducted as previously described, with certain modifications (24). qPCR was performed in a 7300 Real-Time PCR system (Applied Biosystems; Thermo Fisher Scientific, Inc.) in a final volume of $25 \mu \mathrm{l}$ [forward and reverse primers, $0.25 \mathrm{~mol} / \mathrm{l}$ each; Power SYBR $^{\circledR}$-Green PCR Master mix (cat. no. 4367659); and a $1 \mu \mathrm{l}$ cDNA sample]. The thermoycling conditions were as follows: $95^{\circ} \mathrm{C}$ for $10 \mathrm{~min}$, followed by 40 cycles of $95^{\circ} \mathrm{C}$ for $15 \mathrm{sec}$ and $60^{\circ} \mathrm{C}$ for $1 \mathrm{~min}$. PCR primers were as follows: $T Y R$ forward, 5'GAGAAGCGAGTCTTGATTAG3' and reverse, 5'TGGTGC TTCATGCGCAAAATC3'; TRP 1 forward, 5'GGC CTCTGA GGTTCTTTAAT3' and reverse, 5'AATGACAAA TTGAGG GTGAG3'; TRP 2 forward, 5'ATGAGAAACTGCCAACCT TA3' and reverse, 5'AGGAGTGAGGCCAAGTTA TGA3'; MITF forward, 5'AGTACAGGAGCTGGAGATG3' and reverse, 5'GTGAGATCCAGAGTTGTCGT3' (25); $\beta$-actin forward, 5'ATGAGAAGGAGATCACTGC3' and reverse, 5'CTGCGCAAGTTAGGTTTTGT3' (26). Relative expression was analyzed and determined by $2^{-\Delta \Delta \mathrm{Cq}}$ method, normalizing the data to $\beta$-actin mRNA levels $(27,28)$. Experiments were repeated in triplicate.

Western blot analysis. Protein samples that were collected during the melanin content assay was used for western blot analysis. The lysates were denatured in SDS-PAGE protein loading buffer 5X (cat. no. AR1112; Wuhan Boster Biological
Technology, Ltd.) separated on 10\% SDS-PAGE at $80 \mathrm{~V}$, and transferred onto polyvinylidene fluoride membranes for $2 \mathrm{~h}$ at $400 \mathrm{~A}$. Membrane blocking was performed with 5\% skim milk dissolved in TBS with 1\% Tween-20 (TBST) at room temperature for $1 \mathrm{~h}$ and the membrane was incubated with primary antibodies at dilutions of $1: 1,000$ at $4^{\circ} \mathrm{C}$ overnight. Subsequent to washing in TBST, the membranes were incubated with horseradish peroxidase-conjugated secondary antibodies at a dilution of 1:2,000 for $1 \mathrm{~h}$ at room temperature. The membranes were then washed with TBST. Proteins were visualized by enhanced chemiluminescent western blotting detection reagents (GE Healthcare, Chicago, IL, USA). Densitometry analysis was performed using Quantity One version 3 (Bio-Rad Laboratories, Inc.).

Determination of intracellular cAMP levels. B16 melanoma cells were treated with 1,5-diCQA at $0,5,50$ or $100 \mu \mathrm{M}$ at $37^{\circ} \mathrm{C}$ for $12 \mathrm{~h}$. Intracellular cAMP levels were measured using a cAMP ELISA kit (cat. no. STA-500; Cell Biolabs, Inc., San Diego, CA, USA) following the manufacturer's protocol.

Statistical analysis. All data are expressed as mean \pm standard deviation. Statistical analysis was performed by one-way analysis of variance followed by Tukey's post-hoc test for multiple comparisons using SPSS 19.0 (IBM Corp., Armonk, NY, USA) and Graphpad Prism 5 (GraphPad Software, Inc., La Jolla, CA, USA). P $<0.05$ was considered to indicate a statistically significant difference.

\section{Results}

Effect of 1,5-diCQA on B16 cell viability. The total melanin content in the skin is determined by the number of melanocytes and the amount of melanin synthesized by single cells (29). In order to avoid the possibility that effect of melanin synthesis was due to the cell viability, the cytotoxicity of 1,5-diCQA to B16 cells was first determined. B16 cells treated at various concentrations of 1,5-diCQA were incubated for $48 \mathrm{~h}$ and compared with the 1,5-diCQA untreated cells. Cell viability was measured using a CCK assay. The results indicated that 1,5-diCQA exhibited no cytotoxicity at concentration ranges of $0-400 \mu \mathrm{M}$ (Fig. 3A). Concurrently, 1,5-diCQA did not induce any change in cell morphology when compared with the control cells at the concentration of 0-100 $\mu \mathrm{M}$ (Fig. 3B). Accordingly, it was determined that 1,5-diCQA is not cytotoxic to melanoma cells.

Effect of 1,5-diCQA on melanin formation and Tyr activity. The effect of 1,5-diCQA on melanin production in B16 cells was determined by a melanin content assay. As indicated in Fig. 4A and B, intracellular melanin levels increased in response to 1,5-diCQA treatment in a dose- and time-dependent manner, which suggests that 1,5-diCQA may promote melanin synthesis in B16 cells. Fig. 4C denotes the cell precipitation following centrifugation and visual observation. It indicates that cells became darker following the addition of 1,5-diCQA. Studies investigating pigmentary disorders have primarily focused on tyrosinase activity, as it is the most important enzyme in melanin biosynthesis in the melanocytes (30). The results also suggested that 1,5-diCQA promotes intracellular 
B
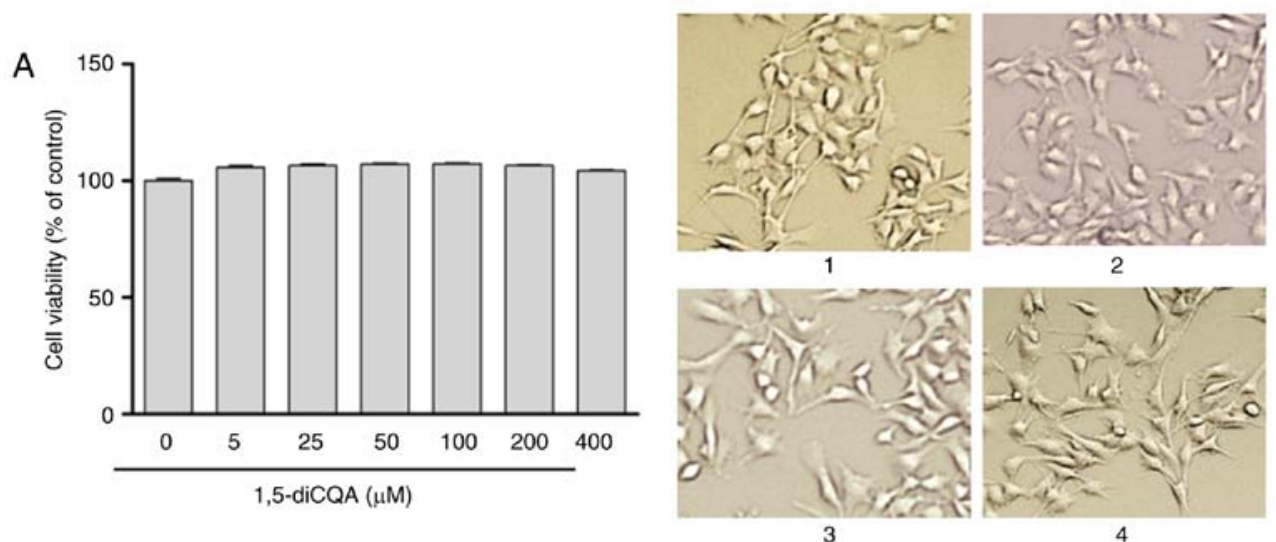

Figure 3. Effects of 1,5-diCQA on B16 cell viability and morphology. (A) B16 cells were treated with $0.1 \%$ dimethyl sulfoxide as a vehicle control, or with 1,5-diCQA at 5, 25, 50, 100, 200 and $400 \mu \mathrm{M}$ for $48 \mathrm{~h}$ and cell viability was measured by CCK assay. (B) Cell morphology was observed under a microscope at magnification, $x 200$. (1) control; (2) 5; (3) 50; and (4) $100 \mu \mathrm{M} 1,5$-diCQA. Values are expressed as the mean \pm standard deviation of three separate independent experiments. 1,5-diCQA, 1,5-dicaffeoylquinic acid.
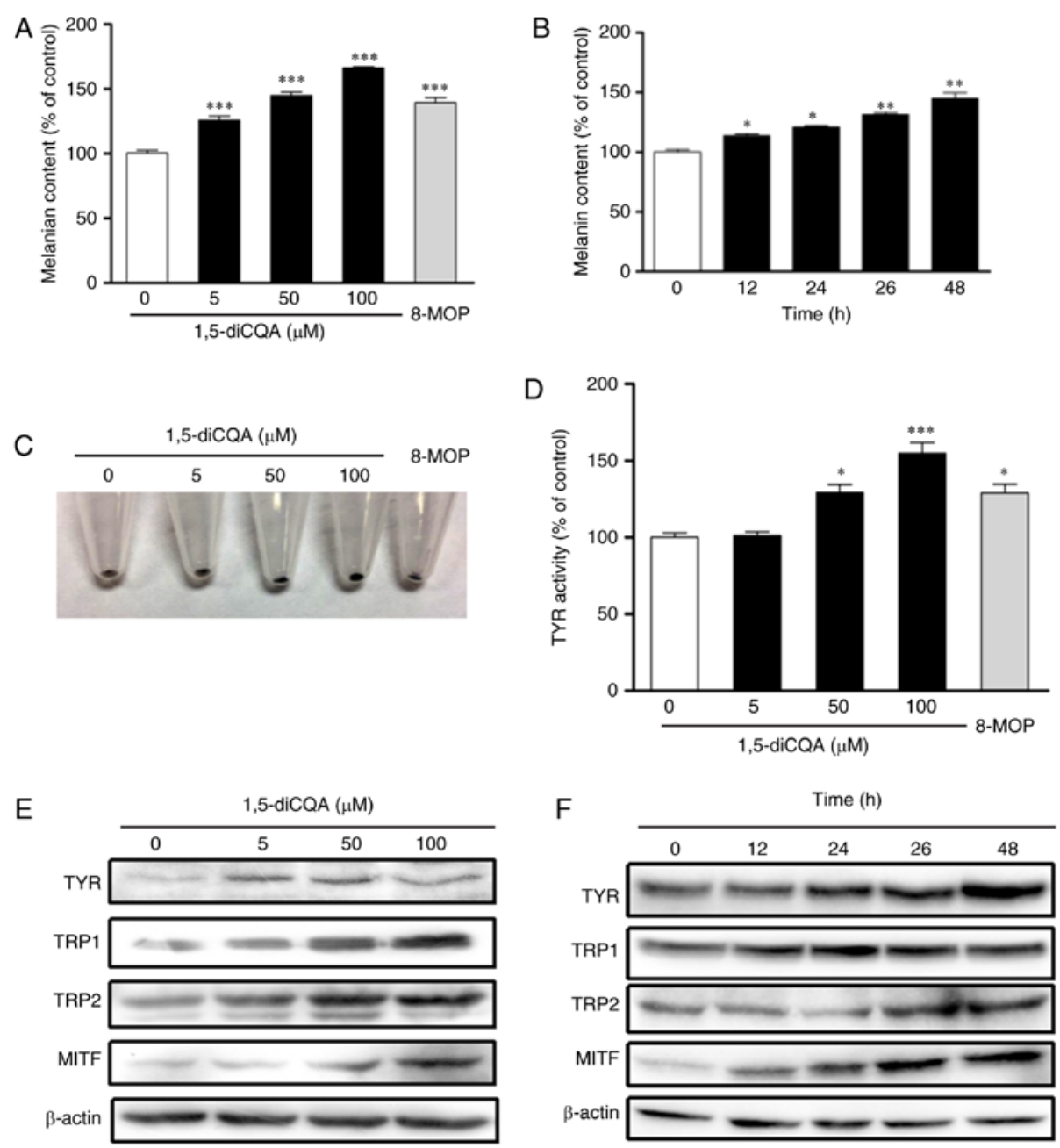

Figure 4. Effects of 1,5-diCQA on the melanin contents in B16 cells. Melanin content was measured in dose- and time-dependent manners. (A) B16 cells were treated with $0.1 \%$ dimethyl sulfoxide as a blank control, 8-MOP $(50 \mu \mathrm{M})$ as a positive control or 1,5-diCQA at 5, 50 and $100 \mu \mathrm{M}$ for $48 \mathrm{~h}$. (B) Melanin content was assayed in a time-dependent manner following treatment with 1,5-diCQA at $50 \mu \mathrm{M}$. (C) B16 cells were treated with 1,5-diCQA at 5, 50 and 100 $\mu \mathrm{M}$ for $48 \mathrm{~h}$, and cell precipitation following centrifugation is indicated. (D) B16 cells were treated with 1,5-diCQA at 5, 50 and $100 \mu \mathrm{M}$ for $24 \mathrm{~h}$, and TYR activity was measured. (E) B16 cells were treated with 1,5-diCQA at 5, 50 and $100 \mu \mathrm{M}$ for $48 \mathrm{~h}$. TYR, TRP1, TRP2 and MITF protein expression levels were detected by western blot analysis, and $\beta$-actin was used as a loading control. (F) B16 cells were treated with $100 \mu \mathrm{M} \mathrm{1,5-diCQA}$ for 0,12, 24,36 and 48 h. TYR, TRP1, TRP2 and MITF protein expression levels were detected by western blot analysis, and $\beta$-actin was used as a loading control. Values are expressed as the mean \pm standard deviation of three separate independent experiments. Each percentage value in the treated cells was calculated with respect to that in the control cells. ${ }^{*} \mathrm{P}<0.05,{ }^{* *} \mathrm{P}<0.01$ and ${ }^{* * *} \mathrm{P}<0.001$ vs. control group. TYR, tyrosinase; TRP-1, tyrosinase-related protein 1; TRP-2, tyrosinase-related protein 2 ; MITF, microphthalmia-associated transcription factor; 1,5-diCQA, 1,5-dicaffeoylquinic acid. 
TYR

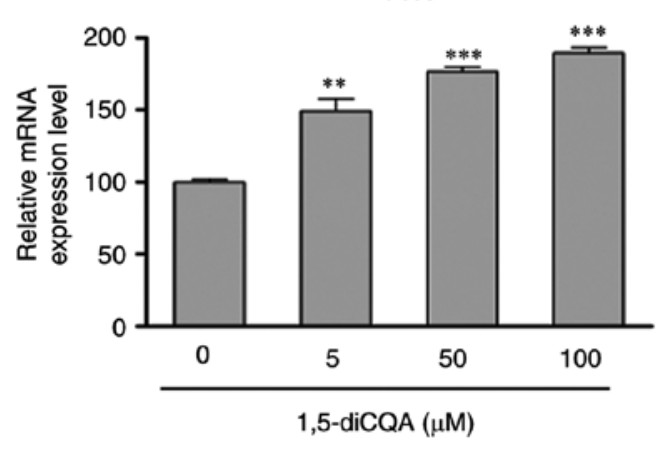

TRP 2

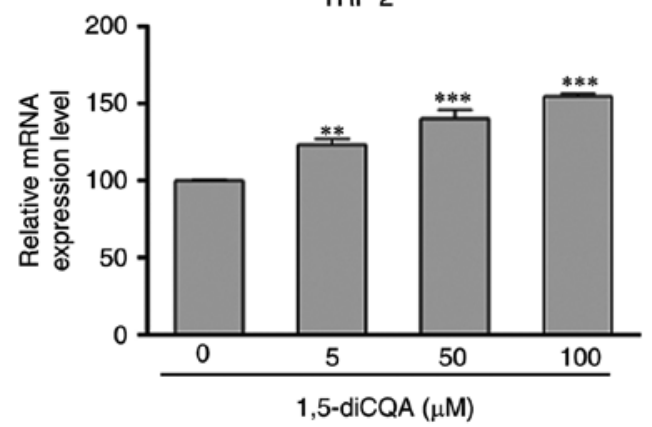

TRP 1

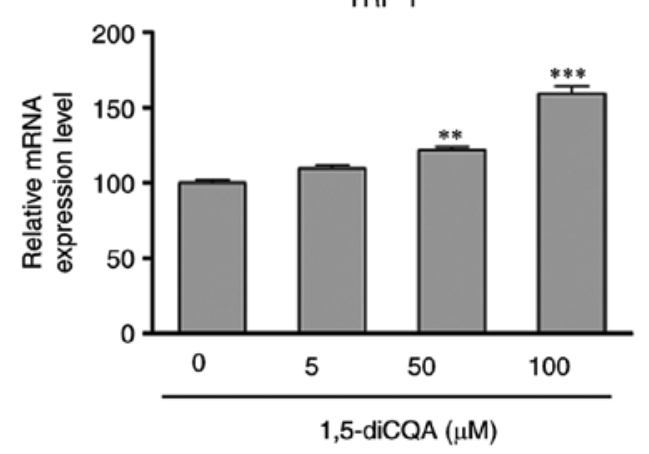

MITF

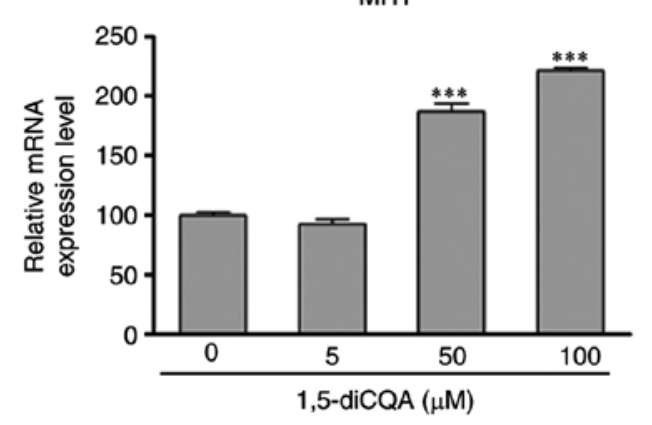

Figure 5. Effects of 1,5-diCQA on the transcriptional TYR family and MITF. B16 cells were treated with 1,5-diCQA at 5, 50 and $100 \mu \mathrm{M}$ for $24 \mathrm{~h}$. The mRNA levels of TYR family and MITF were detected using reverse transcription quantitative polymerase chain reaction. ${ }^{* *} \mathrm{P}<0.01$ and ${ }^{* * * *} \mathrm{P}<0.001$ vs. untreated control. TYR, tyrosinase; MITF, microphthalmia-associated transcription factor; 1,5-diCQA, 1,5-dicaffeoylquinic acid.

Tyr activity in B16 cells in a dose-dependent manner after $24 \mathrm{~h}$ of treatment (Fig. 4D).

Effects of 1,5-diCQA on the expression of melanogenesis-associated genes. The effect of 1,5-diCQA on the expression of melanogenic genes was additionally explored by western blot analysis and RT-qPCR. Western blot analysis indicated that 1,5-diCQA significantly increased the protein expression levels of melanogenic genes TYR, TRP 1, TRP 2 and transcription factor MITF in a dose- and time-dependent manner (Fig. 4E and F). In order to confirm whether the changes in these protein expressions were due to the changes in RNA levels, the effects of 1,5-diCQA on mRNA levels was also detected, and RNA levels of MITF and its downstream genes $T Y R, T R P 1$, and TRP 2. The results demonstrated that the transcriptional levels of MITF, TYR, TRP 1, and TRP 2 were significantly increased in B16 cells in the presence of 1,5-diCQA in a dose-dependent manner (Fig. 5).

Effects of 1,5-diCQA on the MAPK and Wnt signaling pathways. It has been demonstrated that the phosphorylation of MAPK and signaling cascades of ERK, JNK and p38 regulate melanin production (31). As the results of the present study indicated that 1,5-diCQA increased melanin production via the induction of the melanogenic enzyme and pigmentation-associated transcription factor MITF, the melanin-associated signal pathways involved were additionally explored. To investigate the involvement of the MAPK signal pathway in 1,5-diCQA-promoted melanin synthesis, western blot analysis was performed on B16 cells following 1,5-diCQA treatment. The results demonstrated that the phosphorylation levels of p38 and ERK, but not JNK, were

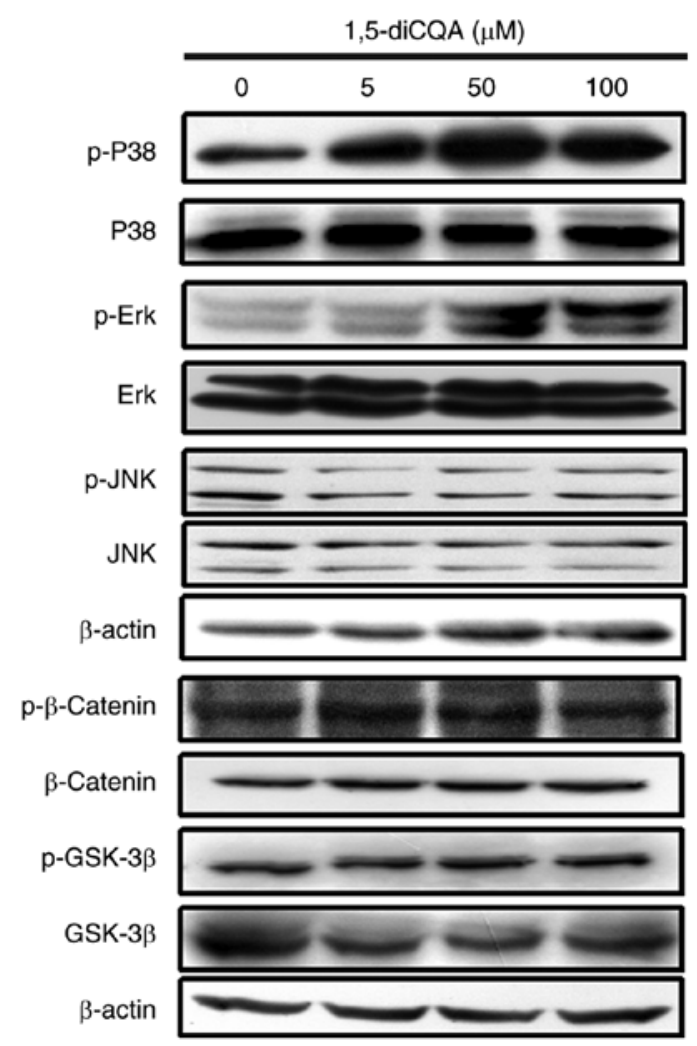

Figure 6. Effects of 1,5-diCQA on the MAPK and Wnt signal pathways. B16 cells were treated with 5,50 and $100 \mu \mathrm{M} 1,5-\mathrm{diCQA}$ for $30 \mathrm{~min}$, and total and phosphorylated forms of p38, ERK and JNK was measured by western blot analysis. Levels of total and phosphorylated forms of $\beta$-catenin and GSK-3 $\beta$ were measured following treatment with 1,5-diCQA for $48 \mathrm{~h}$. p, phosphorylated; MAPK, mitogen-activated protein kinase; P38, p38 MAPK; ERK, extracellular signal-regulated kinase; JNK, c-Jun N-terminal kinase; GSK-3 $\beta$, glycogen synthase kinase 3 $3 ; 1,5$-diCQA, 1,5-dicaffeoylquinic acid. 

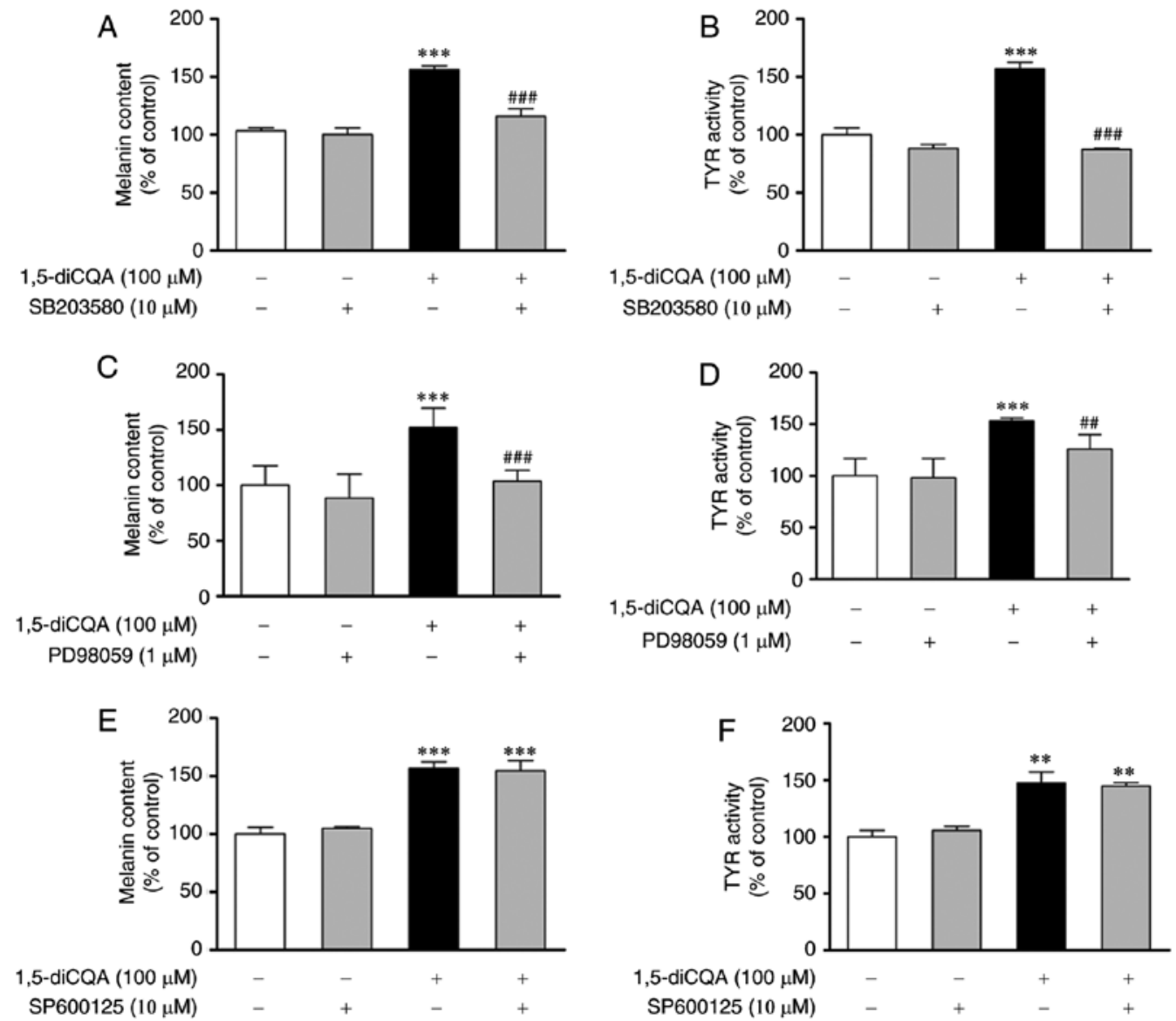

Figure 7. Effects of p38, ERK and JNK inhibitors on 1,5-diCQA-induced melanin synthesis. B16 cells were pre-incubated with SB203580 (10 $\mu \mathrm{M})$ for $2 \mathrm{~h}$ prior to the addition of 1,5-diCQA $(100 \mu \mathrm{M})$, and then (A) incubated for $48 \mathrm{~h}$ for the measurement of melanin content or (B) incubated for $24 \mathrm{~h}$ for the measurement of TYR activity. (C) B16 cells were pre-incubated with PD98059 $(10 \mu \mathrm{M})$ for $2 \mathrm{~h}$ prior to the addition of 1,5-diCQA (100 $\mu \mathrm{M})$, and then (C) incubated for $48 \mathrm{~h}$ for the measurement of melanin content or (D) incubated for $24 \mathrm{~h}$ for the measurement of TYR activity. B16 cells were pre-incubated with SP600125 (10 $\mu \mathrm{M})$ for $2 \mathrm{~h}$ prior to the addition of 1,5-diCQA $(100 \mu \mathrm{M})$, and then (E) incubated for $48 \mathrm{~h}$ for the measurement of melanin content or $(\mathrm{F})$ incubated for $24 \mathrm{~h}$ for the measurement of TYR activity. Each percentage value in the treated cells was calculated with respect to that in the control cells. Values are expressed as the mean \pm standard deviation of three separate independent experiments. ${ }^{* *} \mathrm{P}<0.01$ and ${ }^{* * * *} \mathrm{P}<0.001$ vs. untreated control group. ${ }^{\# \#} \mathrm{P}<0.01$ and ${ }^{\# \# \#} \mathrm{P}<0.001$ vs. single drug treatment group. P38, p38 mitogen-activated protein kinase; ERK, extracellular signal-regulated kinase; JNK, c-Jun N-terminal kinase; 1,5-diCQA, 1,5-dicaffeoylquinic acid.

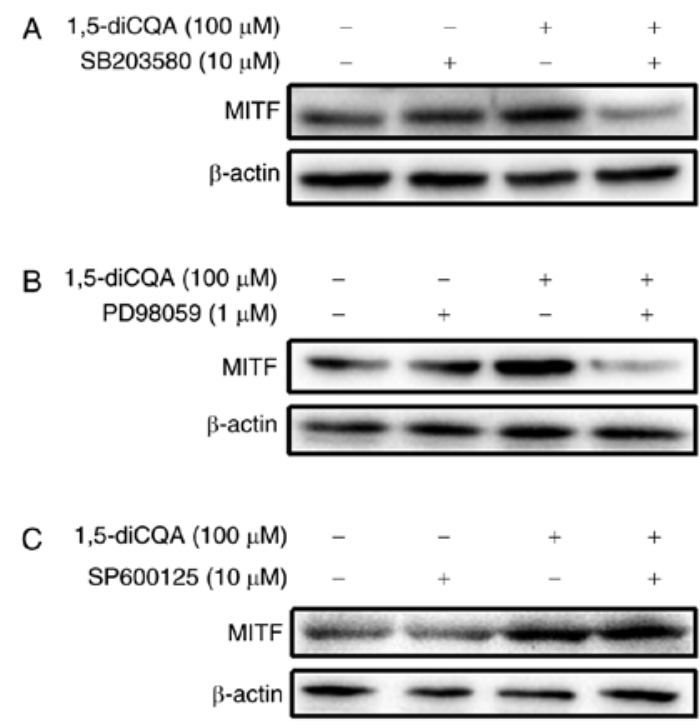

Figure 8. Effects of p38 mitogen-activated protein kinase, extracellular signal-regulated kinase and c-Jun N-terminal kinase inhibitors on 1,5-diCQA-induced MITF expression. B16 cells were pre-incubated with (A) SB203580 $(10 \mu \mathrm{M})$, (B) PD98059 $(1 \mu \mathrm{M})$ or (C) SP600125 $(10 \mu \mathrm{M})$ for $2 \mathrm{~h}$ prior to the addition of 1,5-diCQA $(100 \mu \mathrm{M})$, and then incubated for $48 \mathrm{~h}$. MITF expression was measured by western blot analysis. significantly increased following 30 min treatment with different concentrations of 1,5-diCQA (Fig. 6). These data indicated that 1,5-diCQA may increase melanin synthesis by increasing the levels of p38 and ERK phosphorylation. Therefore, inhibitors of p38 (SB203580), ERK (PD98059) and JNK (SP600125) were applied to verify our prior hypothesis. B16 cells were pre-treated with different inhibitors for $2 \mathrm{~h}$ prior to the addition of 1,5-diCQA (100 $\mu \mathrm{M})$. Then, melanin content and Tyr activities were measured. The results indicated that SB203580 and PD98059 may reverse the 1,5-diCQA effects on melanin content and TYR activities (Fig. 7A-D). However, no effects from the JNK inhibitor (SP600125) were observed (Fig. 7E and F), which was consistent with the western blotting results. In addition, MITF expression was measured by western blot analysis following treatment with SB203580, PD98059, SP600125 and 1,5-diCQA (100 $\mu \mathrm{M})$ for $48 \mathrm{~h}$ (Fig. 8). The results also indicate that 1,5-diCQA increased melanin content through the phosphorylation of p38 and ERK, but not JNK.

The Wnt signal pathway was demonstrated to be closely associated with melanin synthesis (32). In order to investigate whether the Wnt signal pathway was involved in the effects 

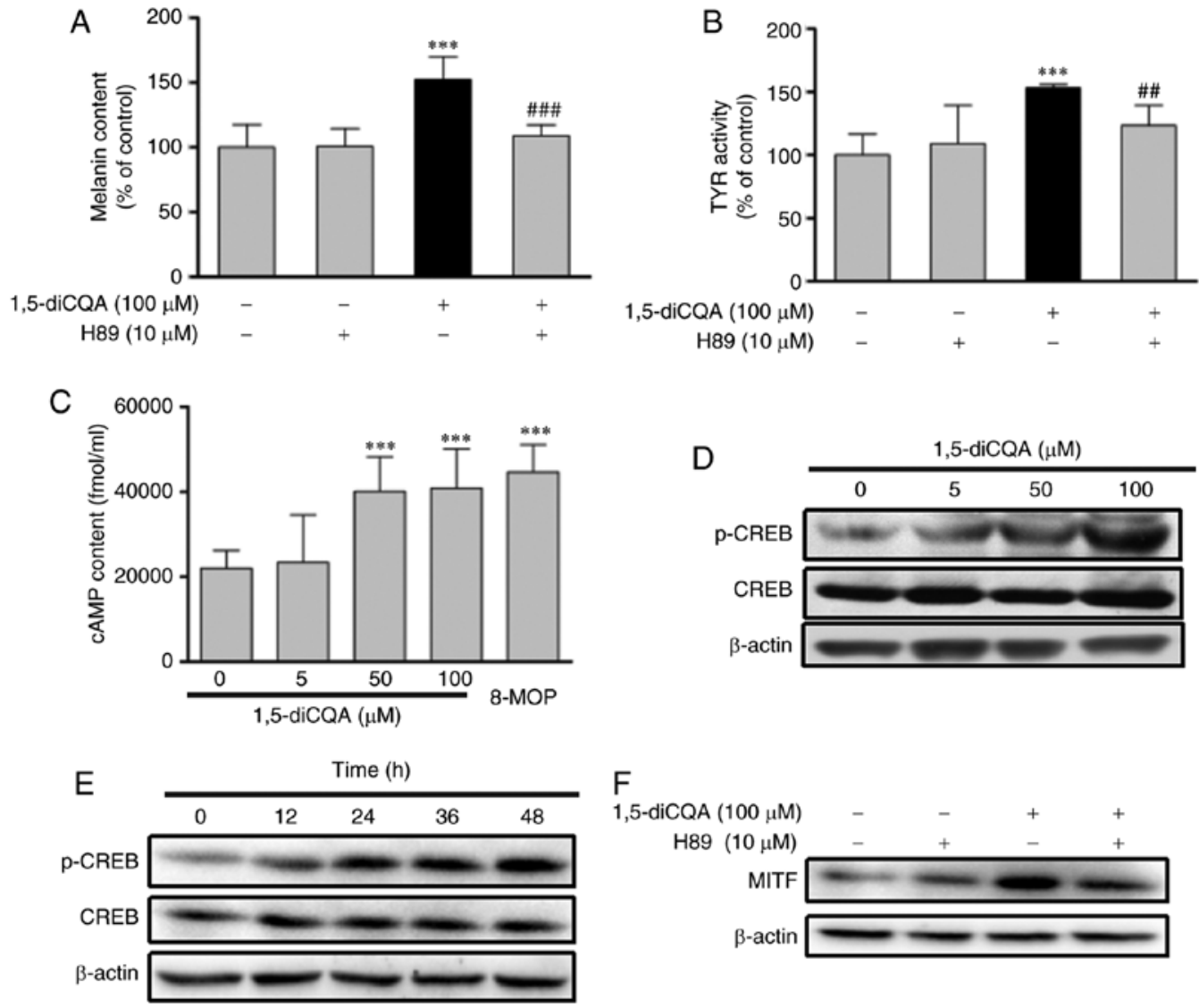

Figure 9. Effects of 1,5-diCQA on the PKA signal pathway. B16 cells were pre-incubated with H89 $(10 \mu \mathrm{M})$ for $2 \mathrm{~h}$ prior to the addition of 1, 5-diCQA $(100 \mu \mathrm{M})$, and then (A) incubated for $48 \mathrm{~h}$ for the measurement of melanin content or (B) incubated for $24 \mathrm{~h}$ for the measurement of TYR activity. (C) B16 cells were treated with $0.1 \%$ dimethyl sulfoxide and 8-MOP as positive controls or 1,5-diCQA at 5,50 and $100 \mu \mathrm{M}$ for $12 \mathrm{~h}$, and then cAMP content was measured by a cAMP-ELISA kit. (D) B16 cells were treated with 5, 50 and $100 \mu \mathrm{M} \mathrm{1,5-diCQA} \mathrm{for} 48 \mathrm{~h}$, and levels of total and phosphorylated CREB were measured by western blot analysis. (E) B16 cells were treated with 1,5-diCQA $(100 \mu \mathrm{M})$ for $0,12,24,36$ and $48 \mathrm{~h}$, and levels of total and phosphorylated CREB were measured by western blot analysis. (F) B16 cells were pre-incubated with $\mathrm{H} 89(10 \mu \mathrm{M})$ for $2 \mathrm{~h}$ prior to the addition of 1,5-diCQA (100 $\mu \mathrm{M})$, and then incubated for $48 \mathrm{~h}$. MITF expression levels were the measured by western blot analysis. ${ }^{* *} \mathrm{P}<0.01$ and ${ }^{* * * *} \mathrm{P}<0.001$ vs. untreated control group. ${ }^{\# \#} \mathrm{P}<0.01$ and ${ }^{\# \# \# "} \mathrm{P}<0.001$ vs. single treatment group. PKA, protein kinase A; TYR, tyrosinase; MITF, microphthalmia-associated transcription factor; 1,5-diCQA, 1,5-dicaffeoylquinic acid; p-phosphorylated; CREB, cAMP-response element binding protein.

of 1,5-diCQA on melanogenesis, the changes in $\beta$-catenin and GSK-3 $\beta$ in B16 cells following treatment with 1,5-diCQA were measured by western blot analysis. B16 cells were treated with 5, 50 and $100 \mu \mathrm{M}$ 1,5-diCQA for $48 \mathrm{~h}$, and total and phosphorylated forms of $\beta$-catenin and GSK-3 $\beta$ were measured. The results indicated that neither total nor phosphorylated $\beta$-catenin and GSK-3 $\beta$ were altered following 1,5-diCQA treatment (Fig. 6).

Effects of 1,5-diCQA on the PKA signaling pathway. It is well-known that the PKA signaling pathway is involved in melanogenesis. Increased cellular cAMP levels may activate PKA. In turn, activated PKA may activate CREB, leading to the upregulation of MITF transcription (33). Therefore, to determine whether the effects of 1,5-diCQA on melanogenesis were also mediated by the PKA signal pathway, a range of experiments using the PKA inhibitor H89 were conducted to identify if PKA affected this process. B16 cells were pre-incubated with $\mathrm{H} 89(10 \mu \mathrm{M})$ for $2 \mathrm{~h}$ prior to the addition of 1,5-diCQA $(100 \mu \mathrm{M})$, and then incubated for $48 \mathrm{~h}$ for the measurement of melanin content and expression of MITF, or incubated for $24 \mathrm{~h}$ for the measurement of TYR activity. The

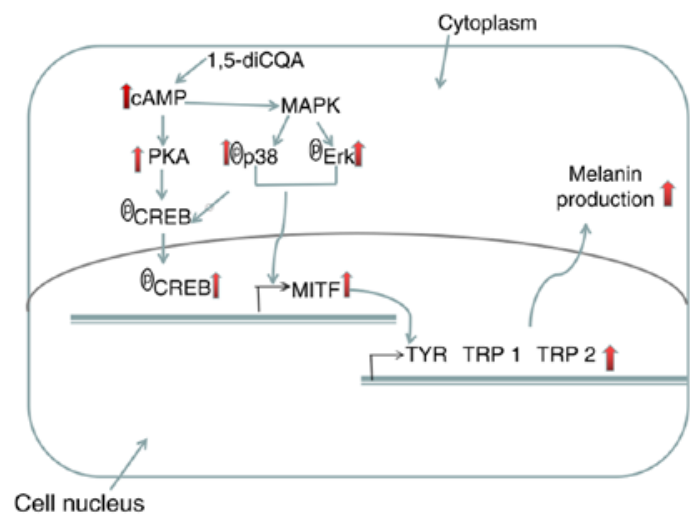

Figure 10. Potential mechanisms through which 1,5-diCQA functions in promoting melanin content in B16 cells. 1,5-diCQA increases the levels of p38 MAPK and ERK MAPK phosphorylation, and therefore increases the activation of MITF. 1,5-diCQA increase the cAMP content, which activates PKA that subsequently phosphorylates CREB. CREB binds to the CRE motif of the MITF promoter and activates MITF transcription TYR, tyrosinase; TRP-1, tyrosinase-related protein 1; TRP-2, tyrosinase-related protein 2; MITF, microphthalmia-associated transcription factor; 1,5-diCQA, 1,5-dicaffeoylquinic acid; MAPK, mitogen-activated protein kinase; P38, p38 MAPK; ERK, extracellular signal-regulated kinase; cAMP, intracellular cyclic adenosine monophosphate; CREB, cAMP-response element binding protein; PKA, protein kinase A. 
results indicated that the effects of 1,5-diCQA on melanogenesis were inhibited following pre-incubation with H89 (Fig. 9A and B). MITF expression was also decreased in the samples that were treated with $\mathrm{H} 89(10 \mu \mathrm{M})$ and 1,5-diCQA $(100 \mu \mathrm{M})$ (Fig. 9F). In addition, cAMP content of the B16 cells following treatment with 1,5-diCQA was measured. The results confirmed that CAMP content was also significantly increased in response to 1,5-diCQA treatment in a dose-dependent manner (Fig. 9C). The levels of CREB induced by PKA, which may activate $M I T F$ transcription levels, were also investigated using western blot analysis. Phosphorylation of CREB was significantly increased following treatment with 1,5-diCQA in time- and dose-dependent manners. (Fig. 9D and E).

\section{Discussion}

Melanin serves a pivotal role in solar UV irradiation-induced skin injury. Lack of melanin is involved in the development of skin diseases, including vitiligo and albinism (34). At present, a number of studies have focused on the specific mechanisms, including the induction of melanin biosynthesis and functional melanocytes, with the aim of developing novel therapeutic agents for vitiligo (35-37). Kaliziri is a plant that only grows in high-altitude areas of southern Xinjiang (China) and small regions of Pakistan and India. The seeds of Kaliziri have historically been used for treating skin diseases including vitiligo in Traditional Chinese medicine (16). Our study group have focused on identifying novel compounds in Kaliziri, and have isolated 1,5-diCQA using high performance liquid chromatography (HPLC) and preparative HLPC, which may be the active ingredient $(38,39)$. Previous studies suggested that methyl 3,5-dicaffeoylquinate and 3,5-di-caffeoylquinic acid, two different structural analogues of 1,5-diCQA, induce melanin synthesis $(40,41)$. Therefore, we hypothesized that 1,5-diCQA may have effects on melanin synthesis. In the present study, the effects of 1,5-diCQA on skin pigmentation induction and its underlying mechanism were investigated. The results indicated that 1,5-diCQA increased melanin production by the induction of the pigmentation-associated transcription factor MITF and melanogenic enzymes TYR, TRP 1 and TRP 2 . Then, the present study attempted to elucidate the molecular mechanism of melanogenesis induction by 1,5-diCQA.

There are certain melanin-associated signal pathways involved in this process, through affecting the pigmentation-associated transcription factor MITF (42). It was demonstrated that p38 MAPK activation contributes to melanin production by activating CREB, which in turn activates MITF expression (43). In addition, the ERK MAPK pathway is also involved in melanogenesis (44). Therefore, the present study examined the effect of 1,5-diCQA on the MAPK signal pathway. It was identified that 1,5-diCQA upregulated the phosphorylation levels of ERK MAPK and p38 MAPK, while levels of JNK MAPK phosphorylation remained the same. This suggested that the p38 MAPK and ERK MAPK pathways may contribute to the stimulation of melanin production.

1,5-DiCQA is a structural analogs of isochlorogenic acid A, which stimulates melanin synthesis via the Wnt signaling pathway (41). Therefore, the present study examined the effect of 1,5-diCQA on the Wnt signal pathway. However, the levels of total and phosphorylated GSK-3 $\beta$ and $\beta$-catenin, which are key proteins in the Wnt signal pathway (13), were demonstrated to be similar prior and subsequent to 1,5-diCQA treatment. This indicates that the Wnt signaling pathway is not a major factor of 1,5-diCQA-induced melanin synthesis.

It has been demonstrated that cAMP up-regulation activates MAPK in B16 cells and normal human melanocytes (45). The cAMP signal pathway is modulated via the MAPK and PKA pathways during melanin synthesis (46). Once intracellular cAMP is accumulated, it activates PKA that subsequently phosphorylates CREB. Then CREB binds to the CRE motif of the MITF promoter and activates MITF transcription (12). Therefore, the effects of 1,5-diCQA on the PKA signal pathway was additionally examined. The results indicated that 1,5-diCQA effects may activate the PKA signaling pathway through the accumulation of cAMP content. In turn, activated PKA activates CREB, sequentially leading to the activation of MITF transcription. Eventually, MITF upregulates melanogenic genes, including TYR, TRP 1 and TRP 2 (Fig. 10).

In conclusion, the present study suggested that the 1,5-diCQA purified from Kaliziri promoted melanogenesis in B16 cells by activating the p38 MAPK, ERK MAPK and PKA signaling pathways. Taken together, the present study suggested that 1,5-diCQA may be a useful agent for treating hypopigmentation skin disorders.

\section{Acknowledgements}

Not applicable.

\section{Funding}

The present study was supported by grants from the Key Research and Development Project of Xinjiang Autonomous Region (grant no. 2016B03038-3) and Projects of International Science and Technology Cooperation of the Xinjiang Uyghur Autonomous Region (grant no. 20146020).

\section{Availability of data and materials}

All data generated or analyzed during this study are included in this published article.

\section{Authors' contributions}

HAA and NM conceived and designed the experiments and wrote the paper; NM and XYL performed the experiments; MK analyzed the data; HAA revised the paper.

\section{Ethics approval and consent to participate}

Not applicable.

\section{Patient consent for publication}

Not applicable.

\section{Competing interests}

The authors declare that they have no competing interests. 


\section{References}

1. Boniface K, Seneschal J, Picardo M and Taïeb A: Vitiligo: Focus on clinical aspects, immunopathogenesis, and therapy. Clin Rev Allergy Immunol 54: 52-67, 2018.

2. Schallreuter KU, Bahadoran P, Picardo M, Slominski A, Elassiuty YE, Kemp EH, Giachino C, Liu JB, Luiten RM, Lambe T, et al: Vitiligo pathogenesis: Autoimmune disease, genetic defect, excessive reactive oxygen species, calcium imbalance, or what else?. Exp Dermatol 17: 139-140, 2008.

3. Gupta AK, Gover MD, Nouri K and Taylor S: The treatment of melasma: A review of clinical trials. J Am Acad Dermatol 55: 1048-1065, 2006.

4. Yamaguchi Y and Hearing VJ: Melanocytes and their diseases. Cold Spring Harb Perspect Med 4: a017046, 2014.

5. Pillaiyar T, Manickam M and Jung SH: Recent development of signaling pathways inhibitors of melanogenesis. Cell Signal 40: 99-115, 2017.

6. Rad HH, Yamashita T, Jin HY, Hirosaki K, Wakamatsu K, Ito $\mathrm{S}$ and Jimbow $\mathrm{K}$ : Tyrosinase-related proteins suppress tyrosinase-mediated cell death of melanocytes and melanoma cells. Exp Cell Res 298: 317-328, 2004.

7. Kim YJ and Uyama H: Tyrosinase inhibitors from natural and synthetic sources: Structure, inhibition mechanism and perspective for the future. Cell Mol Life Sci 62: 1707-1723, 2005.

8. Levy C, Khaled M and Fisher DE: MITF: Master regulator of melanocyte development and melanoma oncogene. Trends Mol Med 12: 406-414, 2006.

9. Niu C and Aisa HA: Upregulation of melanogenesis and tyrosinase activity: Potential agents for vitiligo. Molecules 22: E1303, 2017.

10. Yamaguchi $Y$, Brenner $M$ and Hearing VJ: The regulation of skin pigmentation. J Biol Chem 282: 27557-27561, 2007.

11. Gu WJ, Ma HJ, Zhao G, Yuan XY, Zhang P, Liu W, Ma LJ and Lei XB: Additive effect of heat on the UVB-induced tyrosinase activation and melanogenesis via ERK/p38/MITF pathway in human epidermal melanocytes. Arch Dermatol Res 306: 583-590, 2014.

12. Buscà R and Ballotti R: Cyclic AMP a key messenger in the regulation of skin pigmentation. Pigment Cell Res 13: 60-69, 2000.

13. Schepsky A, Bruser K, Gunnarsson GJ, Goodall J, Hallsson JH, Goding CR, Steingrimsson E and Hecht A: The microphthalmia-associated transcription factor Mitf interacts with beta-catenin to determine target gene expression. Mol Cell Biol 26: 8914-8927, 2006.

14. Lin R and Chen YL: Compositae. In: Flora of China. Vol 4. Science Press, Beijing, pp5-8, 1985.

15. Jamil S, Khan RA, Ahmed $S$ and Fatima S: Evaluation of anti-inflammatory and anti-oxidant potential of seed extracts of Vernonia anthelmintica. Pak J Pharm Sci 30: 755-760, 2017.

16. Tuerxuntayi A, Liu YQ, Tulake A, Kabas M, Eblimit A and Aisa HA: Kaliziri extract upregulates tyrosinase, TRP-1, TRP-2 and MITF expression in murine B16 melanoma cells. BMC Complement Altern Med 14: 166, 2014.

17. Yang B, Meng Z, Dong J, Yan L, Zou L, Tang Z and Dou G: Metabolic profile of 1,5-dicaffeoylquinic acid in rats, an in vivo and in vitro study. Drug Metab Dispos 33: 930-936, 2005.

18. McDougall B, King PJ, Wu BW, Hostomsky Z, Reinecke MG and Robinson WE Jr: Dicaffeoylquinic and dicaffeoyltartaric acids are selective inhibitors of human immunodeficiency virus type 1 integrase. Antimicrob Agents Chemother 42: 140-146, 1998.

19. Cao X, Xiao H, Zhang Y, Zou L, Chu Y and Chu X: 1,5-Dicaffeoylquinic acid-mediated glutathione synthesis through activation of Nrf2 protects against OGD/reperfusion-induced oxidative stress in astrocytes. Brain Res 1347: $142-148,2010$.

20. Xiao HB, Cao X, Wang L, Run XQ, Su Y, Tian C, Sun SG and Liang ZH: 1,5-dicaffeoylquinic acid protects primary neurons from amyloid $\beta$ 1-42-induced apoptosis via PI3K/Akt signaling pathway. Chin Med J (Engl) 124: 2628-2635, 2011.

21. Zheng Z, Wang X, Liu P, Li M, Dong $H$ and Qiao X: Semi-preparative separation of 10 caffeoylquinic acid derivatives using high speed counter-current chromatogaphy combined with semi-preparative HPLC from the roots of burdock (Arctium lappa L.). Molecules 23: E429, 2018.
22. Park SY,Jin ML,Kim YH,Kim Y andLee SJ: Aromatic-turmerone inhibits $\alpha$-MSH and IBMX-induced melanogenesis by inactivating CREB and MITF signaling pathways. Arch Dermatol Res 303: 737-744, 2011.

23. Zhou J, Ren T1, Li Y, Cheng A, Xie W, Xu L, Peng L, Lin J, Lian L, Diao Y, et al: Oleoylethanolamide inhibits $\alpha$-melanocyte stimulating hormone-stimulated melanogenesis via ERK, Akt and CREB signaling pathways in B16 melanoma cells. Oncotarget 8: 56868-56879, 2017.

24. Hout DR, Schweitzer BL, Lawrence K, Morris SW, Tucker T, Mazzola R, Skelton R, McMahon F, Handshoe J, Lesperance M, et al: Performance of a RT-PCR assay in comparison to fish and immunohistochemistry for the detection of ALK in non-small cell lung cancer. Cancers (Basel) 9: E99, 2017.

25. Zhu PY, Yin WH, Wang MR, Dang YY and Ye XY: Andrographolide suppresses melanin synthesis through Akt/GSK3 $\beta / \beta$-catenin signal pathway. J Dermatol Sci 79: 74-83, 2015.

26. Zheng MF, Shen SY and Huang WD: DCA increases the antitumor effects of capecitabine in a mouse B16 melanoma allograft and a human non-small cell lung cancer A549 xenograft. Cancer Chemother Pharmacol 72: 1031-1041, 2013.

27. Livak KJ and Schmittgen TD: Analysis of relative gene expression data using real-time quantitative PCR and the 2(-Delta Delta $\mathrm{C}(\mathrm{T})$ ) method. Methods 25: 402-428, 2001.

28. Lu XY, Li JQ, Liu XN, Li XB and Ma J: Characterization and expression analysis of six chitinase genes from the desert beetle microdera punctipennis in response to low temperature. Cryo Letters 35: 438-448, 2014.

29. Smit NP, Kolb RM, Lentjes EG, Noz KC, van der Meulen H, Koerten HK, Vermeer BJ and Pavel S: Variations in melanin formation by cultured melanocytes from different skin types. Arch Dermatol Res 290: 342-349, 1998.

30. Ramsden CA and Riley PA: Tyrosinase: The four oxidation states of the active site and their relevance to enzymatic activation, oxidation and inactivation. Bioorg Med Chem 22: 2388-2395, 2014.

31. Shen T, Heo SI and Wang MH: Involvement of the p38 MAPK and ERK signaling pathway in the anti-melanogenic effect of methyl 3,5-dicaffeoyl quinate in B16F10 mouse melanoma cells. Chem Biol Interact 199: 106-111, 2012.

32. Hart MJ, de los Santos R, Albert IN, Rubinfeld B and Polakis P: Downregulation of beta-catenin by human axin and its association with the APC tumor suppressor, beta-catenin and GSK3 beta. Curr Biol 8: 573-581, 1998.

33. Kim DS, Cha SB, Park MC, Park SA, Kim HS, Woo WH and Mun YJ: Scopoletin stimulates melanogenesis via cAMP/PKA pathway and partially p38 activation. Biol Pharm Bull 14: 2068-2074, 2017.

34. Kaidbey KH, Agin PP, Sayre RM and Kligman AM: Kligman, hotoprotection by melanin-a comparison of black and caucasian skin. J Am Acad Dermatol 1: 249-260, 1979.

35. Sato K, Ando R, Kobayashi Hand Nishio T: 2-Ethoxybenzamide stimulates melanin synthesis in B16F1 melanoma cells via the CREB signaling pathway. Mol Cell Biochem 423: 39-52, 2016.

36. Lee KM, Lee KY, Choi HW, Cho MY, Kwon TH, Kawabata S and Lee BL: Activated phenoloxidase from Tenebrio molitor larvae enhances the synthesis of melanin by using a vitellogenin-like protein in the presence of dopamine. Eur J Biochem 267: 3695-3703, 2000.

37. Kumar R, Parsad D, Rani S, Bhardwaj S and Srivastav N: Glabrous lesional stem cells differentiated into functional melanocytes: New hope for repigmentation. J Eur Acad Dermatol Venereol 30: 1555-1560, 2016.

38. Maimaiti Z, Turak A and Aisa HA: Two new compounds from the seeds of Vernonia anthelmintica. J Asian Nat Prod Res 19: 862-868, 2017.

39. Turak A and Aisa HA: Three new elemanolides from the seeds of Vernonia anthelmintica. J Asian Nat Prod Res 20: 313-320, 2018.

40. Kim HJ, Kim JS, Woo JT, Lee IS and Cha BY: Hyperpigmentation mechanism of methyl 3,5-di-caffeoylquinate through activation of p38 andMITF induction of tyrosinase. Acta Biochim Biophys Sin (Shanghai) 47: 548-556, 2015.

41. Mamat N, Dou J, Lu X, Eblimit A and Haji Akber A: Isochlorogenic acid A promotes melanin synthesis in B16 cell through the $\beta$-catenin signal pathway. Acta Biochim Biophys Sin (Shanghai) 49: 800-807, 2017. 
42. Pei T, Zheng C, Huang C, Chen X, Guo Z, Fu Y, Liu J and Wang Y: Systematic understanding the mechanisms of vitiligo pathogenesis and its treatment by Qubaibabuqi formula. J Ethnopharmacol 190: 272-287, 2016.

43. Ahn JH, Jin SH and Kang HY: LPS induces melanogenesis through p38 MAPK activation in human melanocytes. Arch Dermatol Res 300: 325-329, 2008

44. Yanase H, Ando H, Horikawa M, Watanabe M, Mori T and Matsuda N: Possible involvement of ERK 1/2 in UVA-induced melanogenesis in cultured normal human epidermal melanocytes. Pigment Cell Res 14: 103-109, 2001.

45. Buscà R, Abbe $\mathrm{P}$, Mantoux F, Aberdam E, Peyssonnaux $\mathrm{C}$, Eychène A, Ortonne JP and Ballotti R: Ras mediates the cAMP-dependent activation of extracellular signal-regulated kinases (ERKs) in melanocytes. EMBO J 19: 2900-2910, 2000.
46. Jung HG, Kim HH, Paul S, Jang JY, Cho YH, Kim HJ, Yu JM, Lee ES, An BJ, Kang SC and Bang BH: Quercetin -3-O- $\beta-D-g$ lucopyranosyl- $(1 \rightarrow 6)-\beta$-D-glucopyranoside suppresses melanin synthesis by augmenting p38 MAPK and CREB signaling pathways and subsequent cAMP down-regulation in murine melanoma cells. Saudi J Biol Sci 22: 706-713, 2015.

This work is licensed under a Creative Commons Attribution-NonCommercial-NoDerivatives 4.0 International (CC BY-NC-ND 4.0) License. 